\title{
Ba-Li (Barium-Lithium)
}

\section{H. Okamoto}

[1984Pel] obtained the $\mathrm{Ba}-\mathrm{Li}$ phase diagram in [Massalski2] by thermodynamic modeling based on the experimental phase boundary data of [1958Kel].

[2007Sme] found a new phase $\mathrm{Ba}_{19} \mathrm{Li}_{44}$ by X-ray diffraction and thermal analysis. Figure 1 shows the $\mathrm{Ba}-\mathrm{Li}$ phase diagram reported by [1984Pel] with the additional information on $\mathrm{Ba}_{19} \mathrm{Li}_{44}$.

Table 1 shows Ba-Li crystal structure data summarized by [1984Pel] and new information on $\mathrm{Ba}_{19} \mathrm{Li}_{44}$ reported by [2007Sme].

\section{References}

1958Kel: D.V. Keller, F.A. Kanda, and A.J. King, Ba-Li Equilibrium System, J. Phys. Chem., 1985, 62, p 732-733

1984Pel: A.D. Pelton, The Ba-Li (Barium-Lithium) System, Bull. Alloy Phase Diagr., 1984, 5(5), p 452-454

2007Sme: V. Smetana, V. Babizhetskyy, G.V. Vajenine, C. Hoch, and A. Simon, Double-Icosahedral Clusters in a New Binary Compound $\mathrm{Ba}_{19} \mathrm{Li}_{44}$ : A Reinvestigation of the Ba-Li Phase Diagram, Inorg. Chem., 2007, 46(13), p 54255428

Table 1 Ba-Li crystal structure data

\begin{tabular}{|c|c|c|c|c|c|}
\hline Phase & Composition, at.\% Li & Pearson symbol & Space group & Strukturbericht designation & Prototype \\
\hline$(\mathrm{Ba})$ & 0 & $c l 2$ & $\operatorname{Im} \overline{3} m$ & $A 2$ & $\mathrm{~W}$ \\
\hline $\mathrm{Ba}_{19} \mathrm{Li}_{44}$ & 69.8 & $t / 252$ & $I \overline{4} 2 d$ & $\cdots$ & $\cdots$ \\
\hline $\mathrm{BaLi}_{4}$ & 80 & $h P 30$ & $\mathrm{~Pb}_{3} / m m c$ & $\ldots$ & $\ldots$ \\
\hline$(\beta \mathrm{Li})$ & 100 & $c / 2$ & $\operatorname{Im} \overline{3} m$ & $A 2$ & $\mathrm{~W}$ \\
\hline
\end{tabular}

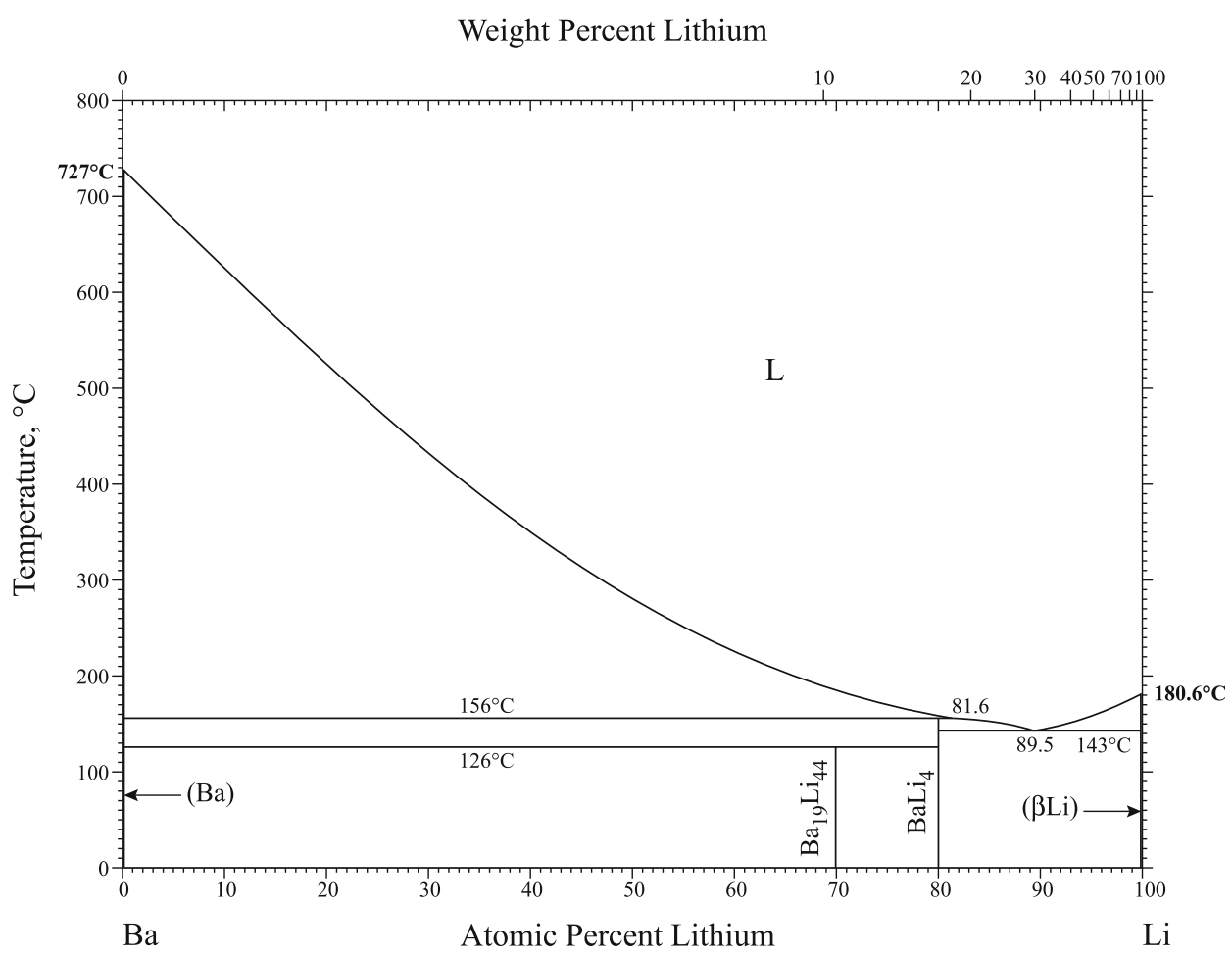

Fig. 1 Ba-Li phase diagram 